\title{
ON THE ARTICLE «GEOLOGICAL CONSEQUENCES OF AMORPHIZATION OF THE LITHOSPHERE AND UPPER MANTLE STRUCTURES CAUSED BY HYDROGEN DEGASSING» BY I. L. GUFELD
}

\author{
A. V. Nikolaev \\ Schmidt Institute of Physics of the Earth RAS, Moscow, Russia
}

Abstract: The commentary discusses possible directions for further research on the complex of issues arising in the analysis of the interaction of ascending hydrogen flows with the solid phase of the lithosphere and upper mantle.

Key words: amorphization of the lithosphere and upper mantle, hydrogen degassing, seismic process.

Citation: Nikolaev A.V., 2012. On the article «Geological consequences of amorphization of the lithosphere and upper mantle structures caused by hydrogen degassing» by I. L. Gufeld. Geodynamics \& Tectonophysics 3 (4), 437-439. doi:10.5800/GT-2012-3-4-0084.

\section{О СТАТЬЕ И.Л. ГУФЕЛЬДА «ГЕОЛОГИЧЕСКИЕ СЛЕДСТВИЯ АМОРФИЗАЦИИ ЛИТОСФЕРЫ И ВЕРХНЕЙ МАНТИИ, ВЫЗВАННЫЕ ВОДОРОДНОЙ ДЕГАЗАЦИЕЙ»}

\author{
А. В. Николаев \\ Институт физики Земли им. О.Ю. Шмидта РАН, Москва, Россия \\ Аннотация: В комментарии рассматриваются возможные направления дальнейших исследований по комплексу во- \\ просов, возникающих при анализе процессов взаимодействия восходящих водородных потоков с твердой фазой ли- \\ тосферы и верхней мантии.
}

Ключевые слова: аморфизация литосферы и верхней мантии, водородная дегазация, сейсмический процесс.

Представленная работа [Gufeld, 2012] в определенной мере является продолжением предыдущей статьи [Gufeld et al., 2011], в которой были сформулированы наши основные проблемы в прогнозе землетрясений. Мы уже многое начинаем понимать, я имею в виду протекание сейсмического процесса, включая действующие силы, особенности и причины возмущений различных параметров блоковой среды. Эти возмущения чаще всего отражали среднесрочные признаки возможной подготовки сильныХ землетрясений, кото- 
рым предшествовало региональное возбуждение среды. Однако оставались вопросы о процессах в граничных структурах, в которых и происходят так называемые крупномасштабные «разрывы». Учитывая то, что долговременное граничное скольжение блоков относительно друг друга осуществляется вдоль весьма тонкого слоя, необходимо было обсудить вопрос о структуре и причинах устойчивости этого слоя. Этот же вопрос возникал при анализе процессов в зоне субдукции.

Идея автора об аморфизации граничных структур вполне логична и находит подтверждение в лабораторном моделировании на горных материалах при имплантации в них водорода или гелия, т.е. атомов внедрения. Хорошо известно в физическом материаловедении, но не учитывалось в геофизике то, что аморфизированные структуры обладают уникальными свойствами, которыми можно объяснить наблюдаемые особенности устойчивого скольжения блоков относительно друг друга. Отсюда же следуют весьма важные выводы о природе сейсмического процесса, сделанные без лишней детализации, что дает основание для постановки работ по прогнозу сильных землетрясений на физической основе с постепенным отказом от эмпирического подхода. Эта часть работы мне наиболее близка. Но необходимо отметить, что содержание работы носит более общий характер, затрагивая также проблемы особенностей граничных структур в литосфере и верхней мантии.

Работа созвучна с идеями академика Ф.А. Летникова по дегазации Земли, высказанными ранее. В совокупности эти работы дополняют друг друга, давая основание для широкого анализа и исследований влияния водородной дегазации на геологические особенности граничных структур планеты, формирование различных месторождений [Letnikov, 2001, 2006]. И.Л. Гуфельд же в представленной работе касается структурных аспектов проблемы взаимодействия водородной дегазации с твердой фазой верхней мантии и литосферы и их следствий. Это оказывается очень полезным для объяснения многочисленных геофизических данных по вариациям скоростей распространения сейсмических волн в мантии и литосфере, а также особенностей реализации глубокофокусных землетрясений. Причем подчеркивается, что скорости распространения сейсмических волн являются структурночувствительными параметрами. Это, кстати, ранее никто не учитывал, списывая все на реакции различных геофизических полей на действие только напряжений. Именно это позволяет связать вариации скоростей, прежде всего быстрых, с изменением структуры водородной подрешетки горной среды. Анализ влияния на аморфизацию структуры атомов внедрения водорода и гелия, действие которых носит пространственный характер, а также C, N, B, F, S, P и некоторых других элементов, влияние которых локально, представляет интерес для обсуждения данных сейсмического про- свечивания, являющихся единственно надежными для изучения глубинных слоев как в пространстве, так и во времени. Делается весьма важный вывод об аморфизации структуры верхней мантии и причинах скоростных неоднородностей по глубине. Роль аморфизации структуры и возможности накопления в ней водорода наглядно проявляются при анализе «глубокофокусных землетрясений» в зонах субдукции, чисто механический аспект которых уже неприемлем.

В дальнейших работах нужно учитывать отмеченные автором барьерный эффект дегазации (подтверждаемый данными Кольской сверхглубокой скважины), образование газовой пористости выше границы Мохо и формирование текстуры деформации. Очень логичен вывод автора о горизонтальном стоке водорода на большие расстояния и его последующей вертикальной диффузии вдоль разломных структур, что подтверждается данными геофизического мониторинга. Именно этот процесс существенно ограничивает в настоящее время наши мониторинговые возможности прогнозирования эпицентральных зон сильных землетрясений. Подчеркну, что эти процессы могут оказывать влияние на формирование гигантских газонефтяных месторождений, что очень важно для оценок запасов и их пополнения во времени.

Есть еще одна проблема, которая прямо не затронута в работе, но вернуться к которой необходимо. Это вообще роль флюида в тектонических движениях и в граничных структурах. Безусловно, флюид с растворенным газом и эффект Ребиндера оказывают влияние на деструкцию среды. Но деструктирующее действие водорода и гелия существенно сильнее, причем имплантация и дегазация водорода и гелия в твердую фазу и из нее вызывают значительные вариации объема элементов структуры, которые могут привести к очень быстрым (сутки) и значительным (метры и более) изменениям уровня воды в скважинах. Эти изменения уровня воды нельзя объяснить медленной тектоникой или действием каких-то фоновых полей. Еще один вопрос. Может ли быть флюид смазкой в граничных структурах? В технических системах вода использовалась лишь для охлаждения деталей, а смазкой являлись специальные вещества со слоистой структурой. У нас же в межблоковых структурах в качестве смазки формируются аморфизированные и текстурированные устойчивые структуры горных материалов. Очень важный вывод для будущих работ по возможному регулированию сейсмического режима.

Рассмотренные в статье проблемы позволяют коллегам представить весь комплекс вопросов, возникающих при анализе процессов взаимодействия восходящих водородных потоков с твердой фазой литосферы и верхней мантии.

Сейчас очевидно, что мы не учитывали ранее во многих направлениях геологии и геофизики один из основных действующих факторов, а именно дегазацию Земли. 


\section{ЛИТЕРАТУРА}

Gufeld I.L., 2012. Geological consequences of amorphization of the lithosphere and upper mantle structures caused by hydrogen degassing. Geodynamics \& Tectonophysics 3 (4), 417-435. http://dx.doi.org/10.5800/GT-2012-3-4-0083.

Gufeld I.L., Matveeva M.I., Novoselov O.N., 2011. Why we cannot predict strong earthquakes in the Earth's crust. Geodynamics \& Tectonophysics 2 (4), 378-415. http://dx.doi.org/10.5800/GT-2011-2-4-0051.

Letnikov F.A., 2001. Ultradeep fluid systems of the Earth and problems of ore formation. Geology of Ore Deposits 43 (4), 259-273.

Letnikov F.A., 2006. Fluids in endogenic processes and problems of metallogeny. Russian Geology and Geophysics 47 (12), 1271-1281.

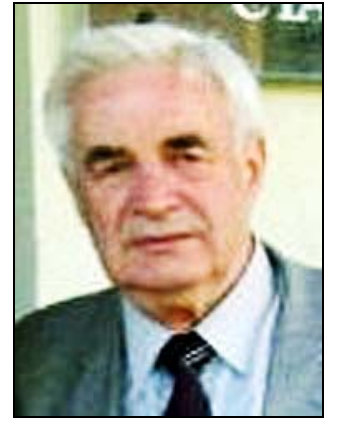

Николаев Алексей Всеволодович, докт. физ.-мат. наук, профессор, член-корреспондент РАН

Председатель Российского экспертного совета по прогнозу землетрясений и оценке сейсмической опасности зав. лабораторией экспериментальной геофизики

Институт физики Земли им. О.Ю. Шмидта РАН

123995, Москва, ГСП-5, ул. Большая Грузинская, 10-1, Россия

$\triangle$ e-mail: nikavs@ifz.ru

Nikolaev, Alexey V., Doctor of Physics and Mathematics, Corresponding Member of RAS

Chairman of the Russian Expert Council for Earthquake Prediction and Seismic Hazard Assessment

Head of Laboratory of Experimental Geophysics

The Schmidt Institute of Physics of the Earth RAS

10-1 Bolshaya Gruzinskaya street, Moscow 123995, Russia

$\triangle$ e-mail: nikavs@ifz.ru 